\title{
Fat Free Mass and Fat Free Mass Index as Reference Variables for Expiratory and Inspiratory Flow Rates
}

\author{
Dr Bipin Bihari Pradhan ${ }^{1}$, Dr Swikruti Behera ${ }^{2}$ \\ ${ }^{1}$ Department of Physiology, M.K.C.G Medical College, Brahmapur, Odisha. \\ ${ }^{2}$ Department of Physiology, M.K.C.G Medical College, Brahmapur, Odisha.
}

\begin{abstract}
Flow rates are very important factors which affect the volume and speed at which air is moved into and out of lung. Body Mass Index and Waist Hip ratio are the most commonly used parameters nowadays to assess obesity and the diseases associated with it. But both the parameters have the limitation of not distinguishing between fat compartment and muscle compartment. Hence this study was taken with the objective that which body composition parameter has highest correlation with flow rates. 150 (85, males; 65, females)healthy medical students 18-24 years age group. Body fat percentage was assessed using 'Bioelectric Impedance' technique.Analysis was done using "GraphPad Prism 6.0" Correlation coefficients and Linear regression equations were used. PEF, PIF \& $M I F_{50}$ have highest correlation with Fat Free Mass (FFM) followed by Fat Free Mass Index (FFMI). $M E F_{25-75} \& M E F_{50}$ have insignificant correlation with all parameters.
\end{abstract}

\section{Introduction:}

The belief that weight shows little or no correlation with pulmonary function measurements ${ }^{1}$ has been abandoned. Nowadays Body Mass Index (BMI) and Waist Hip Ratio (WHR) are commonly used to show the adverse effect of increased weight. Various studies have shown that elevated BMI is associated with impaired Pulmonary Function Parameters ${ }^{2}$. But BMI and WHR have important limitation of not distinguishing between Body Fat \& Body Fat Free Mass (FFM) ${ }^{3}$. Fat free mass includes muscle, bone, water \& blood. Fat percentage is independent of stature and FFM resembles body mass in being correlated with stature. The association of stature with Fat Free Mass is reduced or eliminated by expressing FFM as Fat Free Mass Index (FFMI).

\section{FFMI $=$ FFM/Stature ${ }^{2}$}

Flow rates are very important factors which affect the volume and speed at which air is moved into and out of lung ${ }^{4}$.Flow limitation occurs when airways, which are intrinsically floppy distensible tubes, become compressed when the pressure outside the airways exceed the pressure inside the airways. How and when this occurs and the body composition parameters (Body Mass Index, Body Fat percent, Fat Free Mass, Fat Free Mass Index, Waist Hip ratio) which affect these flow rates are important to understand lung disease.

\section{Methods}

The study was conducted on 150 medical students ( 85 males, 65 females) aged between 17 and 24 years. All the volunteers were apparently healthy without any signs and symptoms. The experimental protocol was explained to all student volunteers and written informed consent was obtained from them. The Institutional Ethical Committee has approved the study, conducted between October 2010 to August 2012. The subjects with history of smoking, asthma, any other past or concurrent pulmonary diseases, and any other systemic diseases were excluded from the study. The study was conducted after a minimum of 2 hours of light breakfast. To avoid circadian variation ${ }^{5}$ all study were conducted between $10 \mathrm{am}$ to 12 noon. All anthropometric measurements such as age, sex, height and weight were recorded. Body weight was recorded in kilograms on empty bladder and before lunch wearing light weight clothing and bare foot with "Prestige Digital Weighing Scale". Standing height was recorded using "stadiometer" to the nearest $0.1 \mathrm{~cm}$. Waist circumference and Hip circumference were measured using measuring tape. Waist by hip ratio was calculated. BMI was calculated using Quetlet's Index-

$$
\mathrm{BMI}=\text { Weight (in } \mathrm{kg}) /\{\text { Height(in meters) }\}^{2}
$$

The body fat percentage was measured by "Bioelectric Impedance" analysis technique using 'OMRON Body Fat Monitor (HBF-306)' . Now FFM (100-Fat $\% \times$ body weight) and FFMI $\left(\mathrm{FFM} / \mathrm{Ht}^{2}\right)$ was calculated.

Pulmonary Function were recorded on a window based "Flowhandy ZaN 100 USB \& ZaN. GPI. 3xx", Germany. Pulmonary function was recorded according to American Thoracic Society Guidelines ${ }^{6}$. 
III. Results:

Observed finding are depicted in the Tables (1-4) and diagram (1-3).

TABLE. 1 DISTRIBUTION ACCORDING TO GENDER

\begin{tabular}{|l|l|l|}
\hline & NUMBERS & PERCENTAGE \\
\hline MALES & 85 & $57 \%$ \\
\hline FEMALES & 65 & $43 \%$ \\
\hline
\end{tabular}

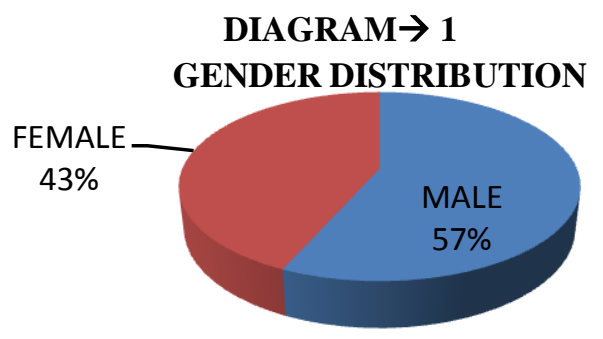

TABLE 2 ANTHROPOMETRIC PARAMETERS (Mean \pm SD)

\begin{tabular}{|l|l|l|l|}
\hline & MALES & FEMALES & p-VALUE \\
\hline HEIGHT(In cm) & $165.55 \pm 5.8608$ & $154.1158 \pm 6.109$ & $<0.0001$ \\
\hline WEIGHT(In kg) & $64.706 \pm 11.7838$ & $56.8153 \pm 11.387$ & $<0.0001$ \\
\hline WAIST CIR(In inches) & $31.846 \pm 2.9081$ & $30.118 \pm 4.147$ & 0.0027 \\
\hline HIP CIR.(In inches) & $36.984 \pm 2.629$ & $35.781 \pm 3.853$ & 0.0222 \\
\hline WAIST/HIP RATIO & $0.8606 \pm 0.04819$ & $0.841 \pm 0.061$ & 0.0196 \\
\hline BMI $\left(\mathbf{k g} / \mathbf{m}^{2}\right)$ & $23.5108 \pm 3.7207$ & $23.9015 \pm 4.4875$ & $0.5556(\mathrm{~ns})$ \\
\hline BF\% & $22.946 \pm 5.1178$ & $31.14 \pm 6.125$ & $<0.0001$ \\
\hline FFM $(\mathbf{k g})$ & $49.4012 \pm 6.7735$ & $38.481 \pm 4.816$ & $<0.0001$ \\
\hline FFMI $\left(\mathbf{k g} / \mathbf{m}^{2}\right)$ & $17.984 \pm 1.9372$ & $16.1866 \pm 1.657$ & $<0.0001$ \\
\hline
\end{tabular}

On 'Unpaired t-test' only BMI was found to be homogenous of all anthropometric parameters in both males and females. These parameters are also depicted in the bar diagram in Diagram $2 \& 3$

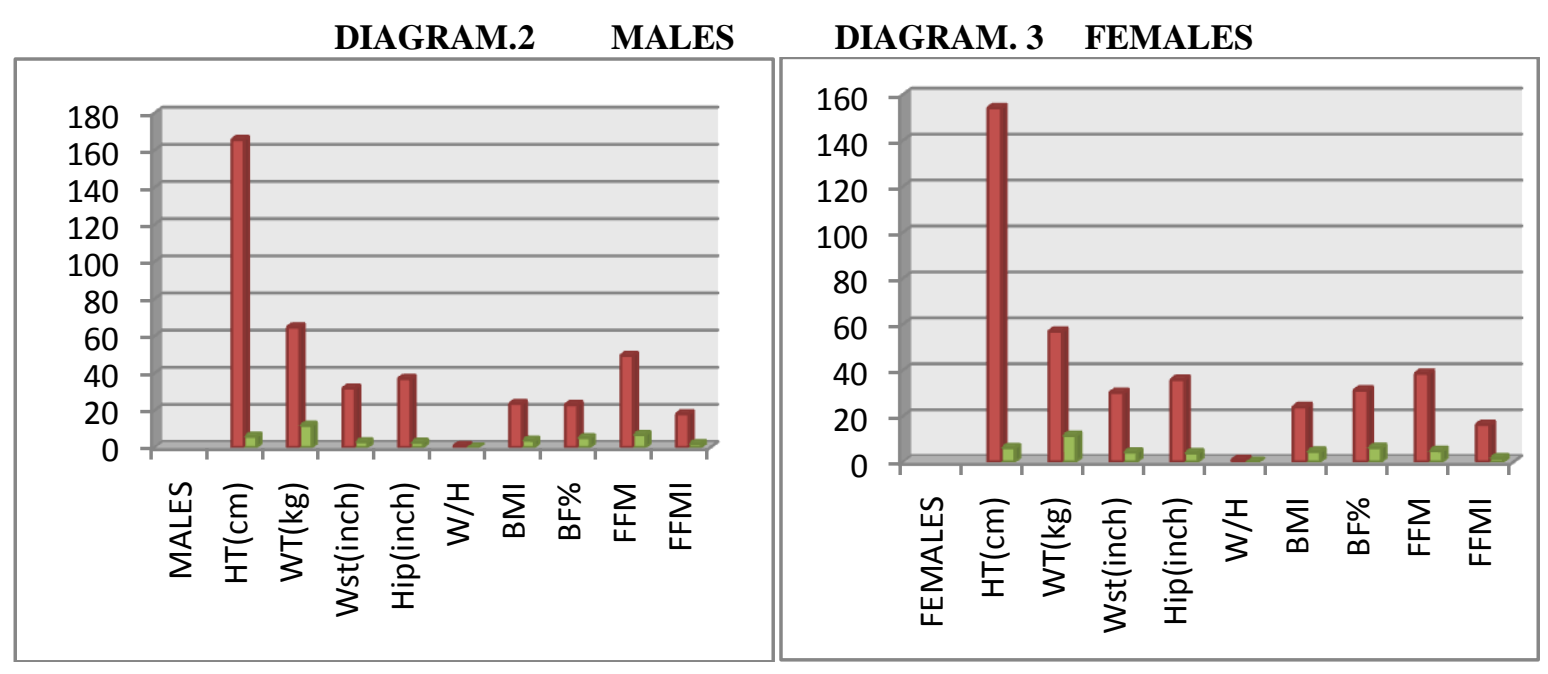

TABLE 3 EXPIRATORY FLOW RATES

\begin{tabular}{|l|l|l|c|}
\hline & MALES & FEMALES & P - VALUE \\
\hline PEF (In lit/min) & $8.063913 \pm 1.468939$ & $6.022615 \pm 1.202697$ & $<0.0001$ \\
\hline MEF $_{50}$ (In lit/min) & $5.17663 \pm 1.176188$ & $4.346615 \pm 1.073016$ & $<0.0001$ \\
\hline MEF $_{25-75}$ (In lit/min) & $4.543043 \pm 0.992674$ & $3.830308 \pm 0.911432$ & $<0.0001$ \\
\hline
\end{tabular}


Fat Free Mass And Fat Free Mass Index...

TABLE 4 INSPIRATORY FLOW RATE

\begin{tabular}{|l|l|l|c|}
\hline & MALES & FEMALES & P - VALUE \\
\hline PIF (In lit/min) & $4.228587 \pm 1.691651$ & $3.221385 \pm 0.999895$ & $<0.0001$ \\
\hline MIF $_{\text {50 }}$ (In lit/min) & $4.0175 \pm 1.705378$ & $3.071385 \pm 1.009338$ & 0.0001 \\
\hline
\end{tabular}

Mean values for expiratory and inspiratory flow rates in both genders were found to be significantly different on

"Unpaired t-test". Hence the flow rates were separately correlated.

Correlation coefficients or "Pearson R" values were determined for each flow rates and body composition parameters.

TABLE 5 CORRELATION COEFFICIENTS, EXPIRATORY FLOW RATES (MALES)

\begin{tabular}{|l|l|l|l|l|l|}
\hline & BMI & BF\% & FFM & FFMI & WHR \\
\hline PEF & 0.03990 & 0.01980 & $\mathbf{0 . 2 5 9 7}$ & 0.05385 & -0.00469 \\
\hline MEF $_{\mathbf{5 0}}$ & -0.07121 & 0.05457 & -0.01591 & -0.1232 & 0.01533 \\
\hline MEF $_{\text {25-75 }}$ & -0.09680 & 0.03223 & -0.03416 & -0.1518 & -0.01615 \\
\hline
\end{tabular}

(All the figures in bold letters are Significant, i.e. $p<0.05$ )

Table 5, collectively shows all the 'Pearson R' values for expiratory flow rates in males. Correlation coefficients of $\mathrm{MEF}_{50}$ and $\mathrm{MEF}_{25-75}$ are insignificant. FFM has highest positive and significant correlation for PEF. Graph- 1 shows the PEF correlation after inserting linear regression equation.

\section{GRAPH $\rightarrow 1$ PEF (MALES)}

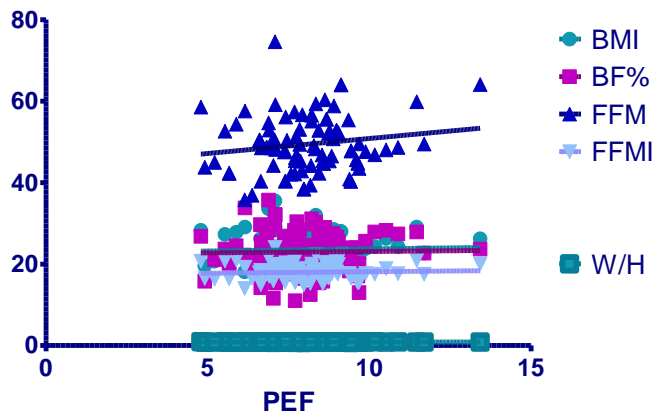

TABLE 6 CORRELATION COEFFICIENTS, INSPIRATORY FLOW RATES (MALES):

\begin{tabular}{|l|l|l|l|l|l|}
\hline & BMI & BF\% & FFM & FFMI & WHR \\
\hline PIF & $\mathbf{0 . 3 5 5 2}$ & $\mathbf{0 . 2 1 4 4}$ & $\mathbf{0 . 4 4 4 5}$ & $\mathbf{0 . 3 8 8 4}$ & $\mathbf{0 . 2 2 2 3}$ \\
\hline MIF $_{\text {50 }}$ & $\mathbf{0 . 3 4 6 2}$ & 0.1987 & $\mathbf{0 . 4 3 6 4}$ & $\mathbf{0 . 3 8 6 3}$ & $\mathbf{0 . 2 1 8 8}$ \\
\hline
\end{tabular}

(All the figures in bold letters are Significant, i.e. $p<0.05$ )

Table -6 , depicts that for inspiratory flow rates in males, FFM is the most important factor followed by FFMI then Waist circumference. BF\% is insignificant for $\mathrm{MIF}_{50}$ and has lowest correlation with BF\%. Graph $-2 \& 3$, depict the relationship on insertion of linear regression equation.

GRAPH 2. PIF (MALES)

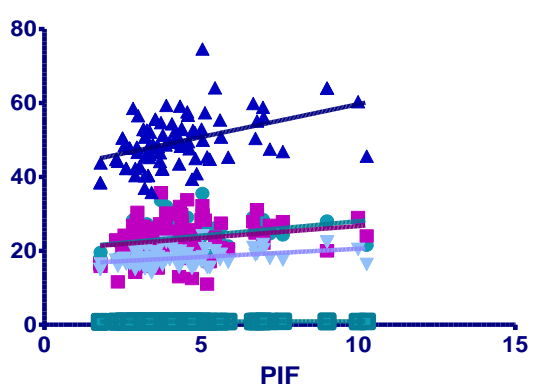

GRAPH 3 MIF $_{50}($ MALES)
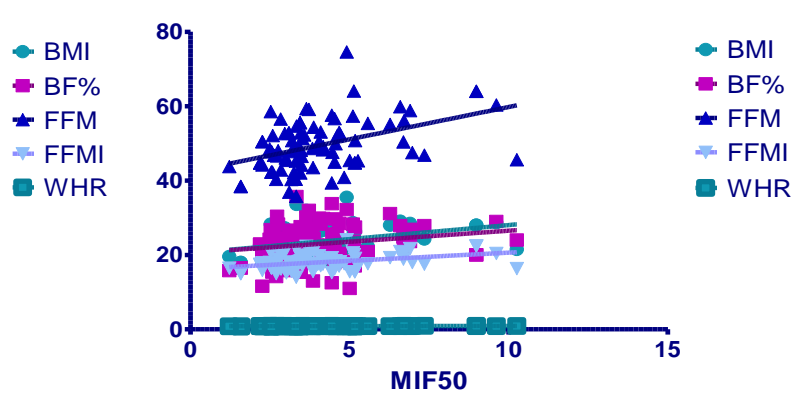
Fat Free Mass And Fat Free Mass Index...

TABLE 7CORRELATION COEFFICIENTS, EXPIRATORY FLOW RATES (FEMALES

\begin{tabular}{|l|l|l|l|l|l|}
\hline & BMI & BF\% & FFM & FFMI & WHR \\
\hline PEF & 0.08391 & 0.01459 & $\mathbf{0 . 4 2 6 9}$ & 0.1867 & -0.02754 \\
\hline MEF $_{\text {50 }}$ & -0.03192 & -0.1079 & 0.2168 & 0.06218 & -0.08789 \\
\hline MEF $_{25-75}$ & -0.07540 & -0.1270 & 0.1579 & -0.0009704 & -0.2086 \\
\hline
\end{tabular}

(All the figures in bold letters are Significant, i.e. $\mathbf{p}<0.05$ )

Table 7, depicts all the correlation coefficients, out of which FFM has highest positive significant correlation with PEF followed by FFMI. $\mathrm{MEF}_{50}$ and $\mathrm{MEF}_{25-75}$ have insignificant but positive correlation with FFM and negative correlation with BF\%. BMI has very low and insignificant correlation with all flow rates. Graph -4 , depicts the same relationship on insertion of linear regression equation.

GRAPH 4 PEF (FEMALES)

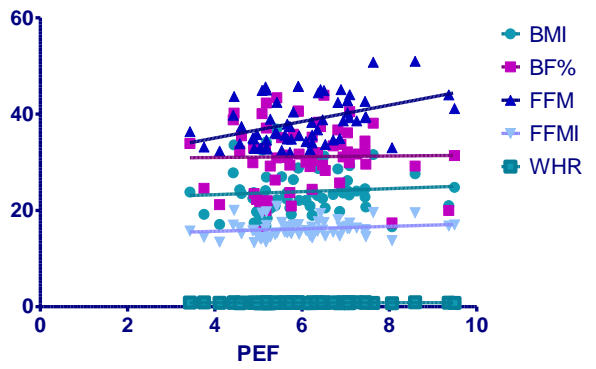

TABLE8CORRELATION COEFFICIENTS, INSPIRATORY FOW RATES (FEMALES)

\begin{tabular}{|l|l|l|l|l|l|}
\hline & BMI & BF\% & FFM & FFMI & WHR \\
\hline PIF & 0.0704 & 0.09266 & 0.1463 & 0.06761 & 0.04819 \\
\hline MIF $_{\mathbf{5 0}}$ & 0.05657 & 0.05532 & 0.09919 & 0.07258 & 0.02767 \\
\hline
\end{tabular}

(All the figures in bold letters are Significant, i.e. $\mathbf{p}<0.05$ )

Table -8 , shows that inspiratory flow rates in females have insignificant correlation with all parameters. But FFM has highest and positive correlation coefficient. Graph $-5 \& 6$, depict the same relationship after insertion of linear regression equation.

\section{GRAPH. 5 PIF (FEMALES)}

GRAPH 6 MIF $_{50}($ FEMALES)
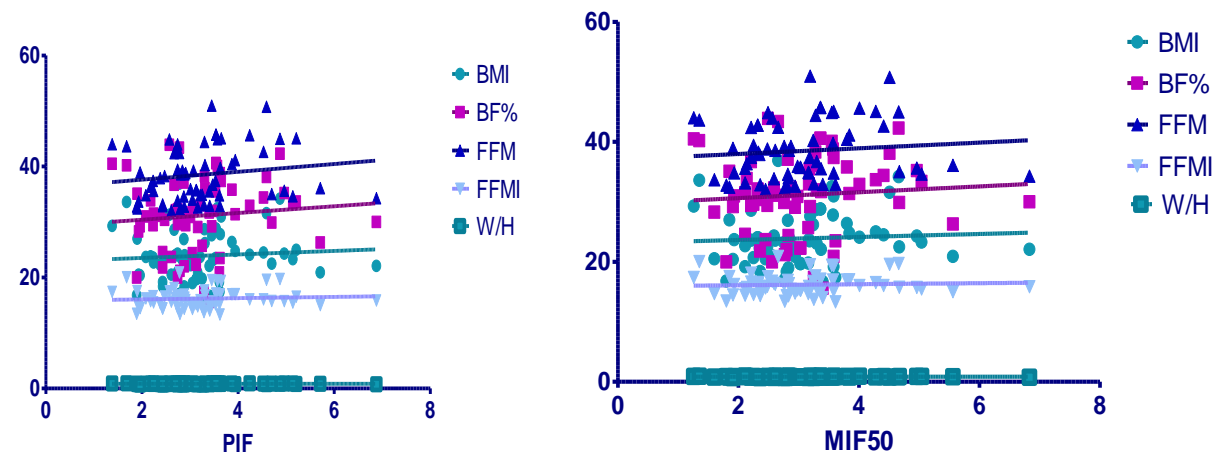

(Table-1 and Diagram -1)

IV. Discussion

In our study is on 150 young subjects between 17 and 24 years out of which 85 were males and $65(43 \%)$ were females. The numbers of volunteers studied were quite high compared to many workers. Lynell C \& Phillip D ${ }^{7}$ had conducted their study on 44 firefighters. Joshi et al' ${ }^{\mathbf{9}}$ studied on 132 males and females overweight students of age group 18-21 years. But here we have taken subjects of random stature irrespective of their BMI and body weight.Ceylan and co-workers ${ }^{\mathbf{1 0}}$ studied only 53 volunteers. Lorenzo and co workers $^{11}$ studied on 30 obese adults. 


\section{Anthropometric parameters of the study group}

(Table-2, Diagram - 2,3)

The mean Height (metres), Weight $(\mathrm{kg}), \quad \mathrm{BMI}\left(\mathrm{kg} / \mathrm{m}^{2}\right)$, Waist circumference(inches), Hip circumference(in inches), Waist hip ratio, Body Fat percentage(BF\%), Fat Free Mass(kg), Fat Free Mass $\operatorname{Index}\left(\mathrm{kg} / \mathrm{m}^{2}\right)$. Mean height for males is $165.6 \mathrm{~cm}$ whereas for females it is little less that is, $154.11 \mathrm{~cm}$. Weight for males is $64.7 \mathrm{~kg}$ and for females it is $56.8 \mathrm{~kg}$. The waist circumference and hip circumference for males are 31.8 inches and 36.9 inches respectively. In females the waist and hip circumference are 30.1 and 35.7 inches respectively. The waist to hip ratio for males and females are 0.8606 and 0.841 respectively. The BMI is within normal range for both males and females. It is 23.5 and 23.9 for males and females respectively. But the fat percentage is $22.9 \%$ in males which is more than the normal range of $8-19 \%$ and in females the average value is $31.14 \%$ which is within normal range of $21-33 \%$. The FFM in males is quite higher than that of females. It is $49.4 \mathrm{~kg}$ in males and $38.48 \mathrm{~kg}$ in females. FFMI in males is $17.9 \mathrm{~kg} / \mathrm{m}^{2}$ and in females it is $16.18 \mathrm{~kg} / \mathrm{m}^{2}$.

Lorenzo and co workers ${ }^{10}$ and Joshi et al ${ }^{9}$ studied on obese adults. Nicholas $\mathbf{S} \mathbf{H}$ and co-workers ${ }^{11}$ studied on 64 patients with stable COPD. Whereas we have studied apparently healthy young adults with random BMI most of them within normal range.

\section{Flow rates in males: (Table $\rightarrow \mathbf{5 , 6}$ Graph $-\mathbf{1 , 2 , 3}$ )}

All the expiratory flow rates have no significant correlation with any of the Body composition parameters as seen in Tables 5 and 6, except PEF which has highest significant positive correlation with FFM. Graph 1, depicts the same by their linear regression equation PEF, which is also termed as maximal expiratory flow rate, occurs shortly after the onset of expiration. The PEF, more than the other measures, is very dependent on patient effort - the patient must initially exhale as hard as possible to obtain reproducible data. This method is particularly valuable in asthma ${ }^{\mathbf{1 4}}$. Our results agree with the finding of $\mathbf{Z u h a l} \mathbf{\&} \mathbf{N i h a l}^{\mathbf{8}} \mathrm{PEF}$ values were lower in obese children than in non-obese children. But instead of using BMI as reference variable we have shown that FFM increase specifically is more helpful in increasing PEF than increase in BF\%, which is also true for BMI which does not differentiate between Fat percent or Fat Free Mass. Our study does not agree with the findings of Joshi et al' according to whom PEFR shows negative correlation with BF\%. But here our study non significant correlation with PEFR and correlation coefficient though positive is of smallest value among all the body composition parameters and FFM has highest (insignificant) 'Pearson R' value among all parameters as seen in Table $\rightarrow 5$.

Muralidhara and Ramesh ${ }^{13}$, Lorenzo and co workers ${ }^{11}$ and Farida and co-workers ${ }^{14}$ did not find any significant PEFR and $\mathrm{FEF}_{25-75}$ changes across groups either in males or females which is similar with our finding.

Lazarus et $\mathbf{a l}^{\mathbf{1 5}}$ found that MMEF does not has significant correlation with any parameters. Our study agrees with the finding of Lazarus et al.

Rumeyza and co-workers ${ }^{\mathbf{1 6}}$ observed that, there was a negative correlation between BMI and FEF50\% and higher BMI or weight levels are associated with lower FEF25\% and FEF50\%. PEF is considered to be an objective measure of airflow resistance in the lungs, which means that there is an increase in respiratory resistance with obesity ${ }^{\mathbf{8}}$. It is likely that the association of higher BMI with lower PEF may indicate that obesity is an important risk factor for reduced airflow or lung function. The reduction in the prevalence of childhood asthma could be related to improved patient awareness and prevention of obesity.Our study agrees with the findings of Canoyet $\mathbf{a l}^{\mathbf{1 7}}$ also found that flow rates were linearly and inversely related across the entire range of waist/hip ratio in both men and women. In our study also $\mathrm{W} / \mathrm{H}$ ratio has insignificant and negative correlations with expiratory flow rates.

Inspiratory Flow Ratesin males as depicted in Tables $\rightarrow 6$ show that all parameters have significant positive correlation with the PIF, but FFM has highest significant correlation coefficient followed by FFMI amongst all

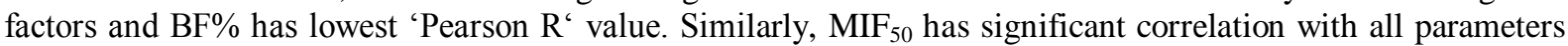
except BF\%. FFM followed by FFMI have highest correlation coefficients. The same relationship is depicted in the Graph-2 \& 3. Regression equations show highest slope for FFM followed by FFMI. Not many studies are present relating to inspiratory flow rates, this value is very important in increasing ventilatory capacity during exercise.Unlike, expiratory flow rates, in which there is a limit to maximal flow, no mechanism such as dynamic compression limits inspiratory flow rate. So, it is very effort- dependent ${ }^{18}$. The main value for testing MIF is to detect lesions in major airway. 


\section{Flow Rates in Females (Table $\rightarrow 7,8$ GRAPH $\rightarrow$ 4, 5, 6) \\ Expiratory Flow Rates (Table $\rightarrow 7$, GRAPH $\rightarrow$ 4)}

PEF shows only significant correlation with FFM. Correlation is positive, i.e. increase in FFM will result in increasing the peak expiratory flow. Other parameters have insignificant correlation with PEF. Muralidhara and Ramesh ${ }^{13}$ observations did not show any correlation of PEF with any body composition parameters. Joshi et $\mathbf{a l}^{9}$ observedthat body fat $\%$ in females also had negative correlation with PEFR. But our study doesn't have any significant correlation with $\mathrm{BF} \%$. Our results also agrees with the finding of Zuhal\& Nihal ${ }^{8} \mathrm{PEF}$ values were lower in obese children than in non-obese children.MEF ${ }_{50}$ and $\mathrm{MEF}_{25-75}$ do not have significant correlation with any body composition parametersIt differs from the observations of Lorenzo and co workers ${ }^{11}$ and Young et al $^{19}$ but agrees with the findings of Muralidhara and Ramesh ${ }^{13}$ and Farida and coworkers ${ }^{14}$.

Inspiratory Flow Rates (Table $\rightarrow \mathbf{8}$, Fig. $\rightarrow \mathbf{5 , 6}$ )

$\mathrm{PIF}$ and $\mathrm{MIF}_{50}$ do not have significant value with any of the body composition parameters as observed in Table $\rightarrow$ 8. The linear regression equation also presents the insignificant graphs representing the same correlation. But though insignificant, FFM has highest positive correlation with Inspiratory flow rates.

\section{Conclusion:}

PEF, PIF and $\mathrm{MIF}_{50}$ in males have highest positive correlation with FFM followed by FFMI. Other flow rates, $\mathrm{MEF}_{50} \& \mathrm{MEF}_{25-75}(\mathrm{MMEF})$ have very low correlation with every factor and are insignificant too. This also goes with the explanation that after $20 \%$ flow, these flow rates are 'Effort - independent'.In females, PEF, PIF and $\mathrm{MIF}_{50}$ have also highest correlation with FFM. Since, these flow rates are 'Effort-dependent' so increase in FFM will also increase the inspiratory flow rates. This study supports the view of the studies that respiratory muscle strength has effect on respiratory function ${ }^{20,21}$. As FFM \& FFMI are direct assessment of muscle amount, so, increasing FFM by various exercises may prove to be useful in improving respiratory function rather than just losing weight.Also making allowances for body composition can improve the accuracy and biological relevance of reference equation for lung function ${ }^{22}$. The use of anthropometric and skinfold measurements has been criticised as being unreliable and inaccurate; they are unable to adequately assess adiposity and are liable to operator bias ${ }^{23}$.Limited usefulness of BMI should be taken into consideration and FFM \& FFMI should be used as reference variable. Measurement of FFM by 'Bioelectrical Impedance' method is inexpensive, reliable, simple, safe and non-invasive technique for use in lung function laboratories ${ }^{24-26}$.

\section{REFERRENCES:}

[1] Consolzia, Toni, Pelona, 1963 .Physiological Measurements of Metabolic Function in Man.P-225

[2] Jones RL, Magdalene M, Nzekwu U. Effects of Body Mass Index on Lung Volume. Chest 2006;130:827-833

[3] Cotes JE, Chinn DJ, Miller MR. Lung Function, Physiology, Measurement and application in Medicine, Blackwell,6 ${ }^{\text {th }}$ Edition: 2006 ; 37-39

[4] Koeppen BM, Stanton BA, Berney and Levy Physiology $6^{\text {th }}$ Edition, 2009, P $-439,440$.

[5] Spengler CM, Cotes SA. Endogenous Circadian Rhythm of Pulm Function in healthy humans. 2002.Am J RespirCrit Care Med ;166: 1005 .

[6] Brusasco V, Crapo R, Viegi G. General consideration for Lung Function Testing. ATS/ERS Task force: Standardisation of Lung function test; EurRespir J. 2005; 26: 153-161

[7] Lynell C, Phillip D, Jenome F, Eugene C, Alan NP, Effect of body fat distribution on pulm function. Test Chest 1995, 1077:12981302

[8] Zuhal G, Eryilmaz N, 2011.Correlation between peak flow and body mass index in obese and non- obese children in Kochaeli, Turkey.Prim Care Respir J 2011; 20(4): 403-406.

[9] Joshi AR, Singh R, Joshi R. Correlation of pulmonary function tests with body fat percentage in young individuals, Indian J PhysiolPharmacol, $2008 ; 52(4): 383-388$.

[10] Ceylan, E., Adurrahmon, Ceylar, Sena The effects of Body fat Distribution on pulmonary function tests in overweight \& Obese 2008

[11] Lorenzo AD, Carmela M, Mohamed EI, Angela A, Patrizia P, Paolo R. Body composition analysis and changes in airway function in Obese adults, after Hypocaloric diet. Chest, 119(5), May 2001: 1409 - 1415

[12] Hopkinson NS, Rachel CT, Mank JD, Elisabeth BS, Trevor TH, John M and Michael IP. A prospective study of decline in Fat Free Mass and skeletal muscle strength in chronic ObstPulm disease. Resp research, 2007; 8:25

[13] Muralidhara DV \& Ramesh M. Some aspects of pulmonary functions in the underweight \& overweight human subjects . The journal of physiological sciences Vol - 20, 2007

[14] Farida M. El-Baz, Eman A. Abdelaziz, AmalAAbdelaziz, Terez B. Kamel, AzaFahmy. Impact of obesity and body fat distribution on pulmonary function of Egyptian children.Egyptian Journal OfBronchology. Vol 3, No 1, June, 2009

[15] Lazarus R, David S, Scott TW, 1997, Effect of obesity and Fat Distribution on Ventilatory Function. CHEST 1997; 111:891-98

[16] Kazancolu R, ÖzbeyN, TetikkurtC, OrhanY. The effect of total body fat and its distribution on respiratory function in obese women. Turkish journal of end \&Metabol (1999) 2 :81-86

[17] Canoy D, Luben R, Welch A, et al. Abdominal Obesity and Respiratory Function in Men and Women in The PICNorfolk Study, United Kingdom. Am J Epidemiol.2004;159:1140-9

[18] Hyatt RE, Scanlon PD, Nakamura M. Interpretation of Pulmonary function Test, A Practical Guide, $3^{\text {rd }}$ Edition, 2009 , p- 14,18.

[19] Parle JP, Pach JH, Jung H. The effect of Body mass index, fat percentage and fat free mass Index on pulmonary function test - with particular reference to parameters derived from forced expiratory Volume Curve :Tub. \& Resp. dis ; $2003: 54$ (2) : $210-218$ 
[20] Nishimura Y, Tsutsumi M, Nakata H, Tsunenari T, Maeda H, Yokohama M. Relationship between muscle strength and lean body mass in men with COPD; Chest 1995;107:1232-1236.

[21] Sanikarya, S, Cimen, OB, Gokcay Y, Erdem R. Pulmonary Function test, Respiratory muscle strength \& endurance of person with obesity. 2007;Sao Paulo Med. J. ;vol.125 (4)

[22] Cotes JE, Chinn DJ, Miller MR. Lung Function, Physiology, Measurement and application in Medicine, Blackwell, $6^{\text {th }}$ Edition: 2006 ;39.

[23] Pullicino E, Coward W, Stubbs RJ, et al. Bedside and field methods for assessing Body Composition : comparison with the deuterium dilution technique. Eur J ClinNutr 1990; 44:753-62.

[24] Khan M, O’ Hara, Pohlman RL, Goldstein DG, Guha SK. Multidimensional applications of Bioelectrical Impedance analysis; JEPonline: 2005; 8 (1): 56-71.

[25] Heyward VH, Wagner DR. Applied body composition.2. Champaign, IL: Human Kinetics; 2004

[26] Lohman TG, Caballero B, Himes JH, Davis CE, Stewart D, Houtkooper L, Going SB, Hunsberger S, Weber JL, Reid R, Stephenson L. Estimation of body fat from anthropometry and bioelectrical impedance in Native American children. Int $J$ ObesRelatMetabDisord. 2000; 24(8): 982-8 